\title{
The Exaggeration of Food Addiction: Most Weight- Controllers are Athletes, not Addicts
}

\begin{abstract}
Food addiction has become a popular notion in the media and the scientific community, with many proposing that an addiction to food causes obesity. Although food addictions may affect some people, this notion may also prove more harmful than helpful. This review explores the concept and implications of food addiction. It first compares food addiction to the diagnostic criteria for substance abuse. It then discusses the empirical evidence of the prevalence of food addiction and binge eating, contrasted with the prevalence of obesity, highlighting important discrepancies. Finally, it summarizes research and expert opinions on food addiction, as well as the potential harm caused by encouraging researchers, healthcare workers, and obese people to view food addiction as a primary cause of obesity. Ultimately, this review concludes that the concept of food addiction does not fit the data or serve the interests of obese people nearly as well as an alternative perspective: viewing weight controllers as athletes, not food addicts.
\end{abstract}

The idea of food addiction has become a popular concept in the media and in the scientific community. Proponents of this idea view addiction to food as the primary explanation for obesity, that people gain excess weight because they are food addicts. Obese people ostensibly use food as their drug of choice. If people struggle to control weight, this food-drug supposedly helps them get through the stresses of everyday life. However, this characterization is problematic in its message to those that wish to lose weight and to successful weight controllers. It portrays anyone who struggles to lose weight as an addict who binge eats. If one manages to control weight, he or she would be considered a food addict in recovery.

Do these notions accurately represent obesity? Indeed, some who are obese believe in this addictive notion to explain their weight problems. For a few of them, it may actually help them understand the power of the biological forces working against their success. For the majority, however, the notion of food addiction may cause more harm than good. The present paper will examine the food addiction proposition first by defining key terms, then by examining the evidence supporting the food addiction hypothesis conceptually and empirically. We will then present evidence supporting the potentially harmful effects of the food addiction model and draw appropriate conclusions.

\section{Food Addictions and Food Addicts: Definitions}

Some researchers argue that the dramatic increases in obesity throughout the world correspond to increasing availability of cheap high fat and high sugar foods [1]. Could it be that people become addicted to such foods - and this powerful force has caused epidemic increases in obesity? Some parallels do exist between the brain chemistry associated with drug addiction and the effects observed

\section{Journal of \\ Obesity and Bariatrics}

\section{Daniel S. Kirschenbaum ${ }^{1,3}$ and Ross Krawczyk ${ }^{2 *}$}

${ }^{1}$ Department of Psychiatry and Behavioral Sciences, Northwestern University Medical School, Chicago, USA

${ }^{2}$ Department of Psychology, The College of Saint Rose, New York, USA

${ }^{3}$ WellStar Health System, Atlanta, USA

\section{*Address for Correspondence}

Ross Krawczyk, Ph.D, Department of Psychology, The College of Saint Rose, 432 Western Avenue, Albany, New York, USA, E-mail: krawczyr@mail.strose.edu

Copyright: (c) 2015 Kirschenbaum DS, et al.This is an open access article distributed under the Creative Commons Attribution License, which permits unrestricted use, distribution, and reproduction in any medium, provided the original work is properly cited.

Submission: 04 February 2015

Accepted: 09 March 2015

Published: 13 March 2015

Reviewed \& Approved by: Dr. Radwan Kassir, Department of General and Bariatric surgery, University Hospital Center of SaintÉtienne, France

(especially in animals) after consuming a lot of sugar [2]. This is particularly true for dopaminergic effects in the brain. However, parallels observed in the brain between addictive drugs and the intake of high doses of sugar make a weak case for the usefulness of the food addiction notion for most weight controllers. Many stimuli, both chemical and behavioral, produce similar changes in brain chemistry. In order to meet a reasonable standard for addiction, researchers have argued that other criteria deserve consideration. Gearhardt and Corbin compared food addiction to the DSM-IVTR criteria for substance dependence [3,4]. DSM-IV-TR defines substance dependence as the presence of serious degree of distress or impairment in functioning and at least three of seven of the following criteria over the past 12 months:

- Tolerance (physiological) to Increasing Amounts of the Substance

- Withdrawal Effects When Use of Substance is Discontinued

- Loss of Control

- Repeated Failed Attempts to Reduce or Stop Consumption

- Substantial Time Spent to Obtain, Use, and Recover from Use of the Substance

- Giving Up Important Other Important Activities

- Continued Use Despite Physical or Psychological Problems

\section{Distress and impairment}

The distress and impairment criterion creates the first problem for considering obesity to result from food addiction. Many overweight people do not view their weight status as a problem, nor are they impaired by it. Cross cultural studies demonstrate this particularly well. Among people from Puerto Rico, researchers found that their participants rated photographs depicting obese individuals (on the mild side of the obesity spectrum) as very attractive [5]. Research shows that some other sub-groups, for example many 
African American men, similarly find such images quite appealing [6]. Certainly most significantly overweight people work, maintain families, and do not show evidence of serious distress or impairment [7]. For example, Fitzgibbon, Stolley, and Kirschenbaum found that overweight people who sought professional help showed more distress than those who had similar weight problems but did not seek help [8]. The latter group, employees at a major teaching hospital, reported the usual level of stresses and strains of everyday life, no more or less.

On the contrary, those who suffer from substance addiction tend to experience significant psychological distress and impairment in functioning. Greenfield and Crisafulli found dramatically elevated levels of psychological distress among those who have substance use addictive disorders (SUDs) compared to population norms [9]. They reported that about $30 \%$ of those with SUDs had mood disorders at some point in their lives compared to $8 \%$ in the general population. They also noted dramatically higher rates (3-20 times higher) among SUDs for a variety of other serious psychological disorders including anxiety disorders, psychotic disorders, and personality disorders. In sharp contrast to people with SUDs, most studies show either no difference in psychological functioning or mild elevations of such problems among obese individuals $[7,10]$.

\section{Tolerance \& withdrawal}

Tolerance, needing an increasing amount of the substance in order to produce the desired effects, is a common feature of addiction. People do not demonstrate tolerance toward foods. No scientific evidence exists to show tolerance to the enjoyment of eating in general, or to the enjoyment of specific foods.

Similar to tolerance, there is a complete lack of evidence for withdrawal symptoms from food. None of the researchers who contributed to the recent edited book by Brownell and Gold, all of whom clearly favor the notion of food addiction, could find any evidence to support the existence of physical withdrawal from certain foods [11]. At an anecdotal level, the authors can report on the incidences of withdrawal symptoms at the leading provider of treatment services for overweight young people in the USA, Wellspring [12-14]. In Wellspring's camps over its first 10 summers of operation (2004-2013), the camp directors did not report a single case of physical symptoms of withdrawal among 8,000 participants. Both teenagers and adults in these programs radically changed their diets (to a very low fat reduced calorie diet) from the first day they begin their immersion experiences in the summer camps or boarding schools. Yet, none of them seemed to have evidenced flu-like symptoms or headaches or any other sign of withdrawal. Actually, they generally have reported feeling better physically almost immediately, with documentation from validated self- and parentreported assessments of dramatic improvements in moods over an average length of stay of 5 weeks in the summer camps [10,14].

\section{Loss of control}

Some obese people do report binge eating [15]. However, when applying this SUD criterion to food addiction, the question of the frequency of such binge eating arises. If the food addiction hypothesis is the best conceptualization of obesity, then the majority of obese people would frequently lose control of their eating. However, the evidence does not support this position [15-17].

The food addiction hypothesis also leads to the hypothesis that obese people who are prevented from binge eating, such as those who participate in intensive, immersive treatment, should exhibit considerable distress. There is evidence for this phenomenon in nonsubstance behaviors. Thaxton found that requiring very consistent runners to stop running for a day made them quite distressed [18]. Yet, in studies of cognitive-behavioral treatment of obesity, participants consistently feel much better as they participate in such programs $[7,14]$. The loss of binge eating for the relatively few who binge regularly failed to cause the distress predicted by the food addiction hypothesis. These findings suggest that binge eating as a means of coping with distress is probably not a major cause obesity.

\section{Repeated failed attempts to reduce or stop consumption}

Unlike the situation in substance abuse, weight controllers clearly would not survive if they discontinued eating altogether. In contrast, research on the thousands of people who have succeeded at weight management shows that it is possible, albeit difficult, to reduce consumption of high fat foods relatively permanently $[19,20]$.

\section{Substantial time spent to obtain, use or recover from use of the substance}

High caloric density foods do not require much effort to buy and consume, nor do they require any recovery after use. Consumption of calorie dense foods does not meet this criterion, but neither do the use of common addictive substances such as cigarettes and caffeine. As in the prior example of repeated failures to succeed, this one also does not do well at discriminating dependence from independence regarding some substances.

\section{Giving up important activities}

The diagnostic criteria for SUD (APA) involve the "failure to fulfill major role obligations" in work, school, or home. If food addiction were a primary cause of obesity, we would expect most obese people to have similar problems [4]. Although obesity is associated with negative consequences, most obese people experience good functioning $[7,8]$. They certainly do not frequently fail to fulfill obligations at work, school, or home due to their "food addiction". Also, many successful weight controllers avoid certain activities and situations, such as those that involve consumption of an excessive number of calories, in order to maintain successful weight control. However, is such restraint synonymous with a failure in obligations or worthy of a designation of dependence on food? Relatively few obese people have binge eating disorders [15]. Of these few, some may also avoid others in order to continue their binges or to recover from binges, which could be classified as a failure of role obligations. However, the infrequency of such behavior, in contrast with the frequency obesity, shows that this criterion for addiction does not match the experience of most obese people. This provides further evidence that the notion of food addiction fails to adequately explain the causes of obesity.

\section{Continued use despite physical or psychological problems}

People with common substance use dependences often continue 
using despite major legal, financial, interpersonal and health problems. Some obese people certainly do continue consuming high calorie foods despite increasing problems resulting from their obesity. However, many use such health problems to motivate themselves to seek treatment and change [20]. Unfortunately, after failing to succeed using a variety of methods, a type of learned helplessness and lack of optimism about success probably contributes to sustained consumption of problematic foods. Self-efficacy, and learned helplessness, provide far better explanations than food addiction $[21,22]$.

\section{Summary and conclusions}

Table 1 summarizes the evidence comparing drug to food addiction on the distressed caveat and the seven criteria used to define substance dependence. The evidence and logic do not support the usefulness of thinking about the causes of obesity as a food addiction or defining most obese people as food addicts.

\section{Binge Eating, Obesity, and Food Addiction: By the Numbers}

In 2007, Hudson, Hiripi, Pope, and Kessler conducted a largescale study using a representative sample of adults in the USA in order to estimate, among other things, the prevalence of binge eating disorder $[4,15]$. If indeed food addiction were a primary cause of obesity, one would expect that the prevalence of binge eating would be near that of obesity. About $69 \%$ of adults in the USA today are either overweight or obese [23]. The Hudson et al. survey revealed that only $2.8 \%$ of adults report any lifetime incident of Binge Eating Disorder [15]. Instead of finding that $100 \%$ of that group of overweight or obese adults had this problem, the researchers found that only $4 \%$ experienced binge eating even for just a few months at any time in their lives. Figure 1 illustrates the percentage of obese people in the USA in contrast with the percentage of binge eaters, a stark contrast of $69 \%$ against $2.8 \%$. Also, many of those observed to be binge eaters were not overweight or obese. $69 \%$ of the approximately 235 million adults in the USA, means there are about 162 million overweight or obese people in the USA. The food addict explanation for obesity suggests that the vast majority should be binge eating, at least 100 million. However, Hudson et al. did not find this. 2.8\% of

Table 1: Drug Addicts versus Obese People Compared on the 8 elements of the diagnosis of substance use dependence (Addiction).

\begin{tabular}{|c|c|c|}
\hline Distressed & Drug Addict & Obese People \\
\hline Tolerance & $\begin{array}{c}\text { Very Frequently } \\
\text { Yes, in most } \\
\text { cases } \\
\text { Yes, in most } \\
\text { cases }\end{array}$ & Sometimes \\
\hline Withdrawal & Yes & No \\
\hline Loss of Control & Yes & $\begin{array}{c}\text { Infrequently } \\
\text { persistence at difficult } \\
\text { tasks good? }\end{array}$ \\
\hline $\begin{array}{c}\text { Repeated Failures } \\
\text { to Change }\end{array}$ & Usually & No \\
\hline $\begin{array}{c}\text { Substantial Time } \\
\text { to Obtain }\end{array}$ & Yes, frequently & Rarely \\
\hline $\begin{array}{c}\text { Giving up Activities } \\
\text { Sustained Use } \\
\text { Despite Problems }\end{array}$ & Yes & $\begin{array}{c}\text { Yes, but necessary for } \\
\text { survival }\end{array}$ \\
\hline
\end{tabular}

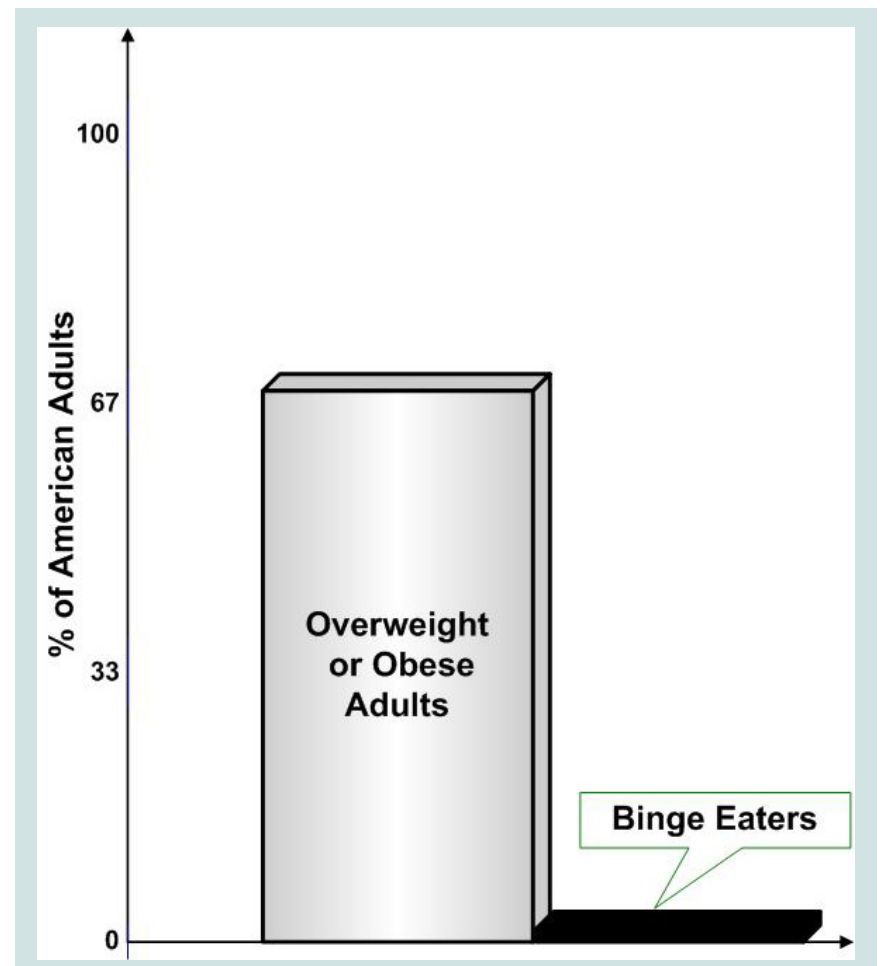

Figure 1: Percentage of American Adults who are Overweight or Obese versus $\%$ who were diagnosed with Binge eating disorder in the survey by Hudson et al. (2007).

the total number of adults is about 6.6 million people [15]. Even if the vast majority of those 6.6 million people were overweight or obese that would mean that only 5-6 million reported this problem. Figure 2 contrasts the 100 million expected by the food addict advocates versus the 6 million observed.

Food addiction advocates believe that those who suffer most from this addiction would struggle far more than others to lose weight $[2,4]$. Consider the clear logic of this. According to the definition of addiction, food addicts, compared to other overweight people, supposedly experience much more distress and hopelessness, binge eat very often, require increasing amounts of food and more binge eating over time, experience withdrawal symptoms when they reduce consumption, and fail repeatedly in their attempts to lose weight. Therefore, food addict believers would predict that overweight food addicts would almost certainly fail to lose weight much more so than non-addicts.

Three recent studies tested this prediction directly. Evaluated 57 obese adults using the Yale Food Addiction Scale (YFAS) $[16,24]$. This scale asks people to indicate the degree to which they experience distress, hopelessness, interference with other aspects of their lives, binge eating beyond their control, withdrawal and related aspects of the definition of binge eating. If participants acknowledge experiencing several of these symptoms quite often, then researchers consider them to be food addicts. The adults studied by Burmeister et al. attempted to lose weight for 7 weeks [16]. YFSA scores did not predict outcomes any better than a simple measure of binge eating. In other words, binge eaters did not lose as much weight as non-binge eaters in this small study, but the YFAS scores revealed nothing more 


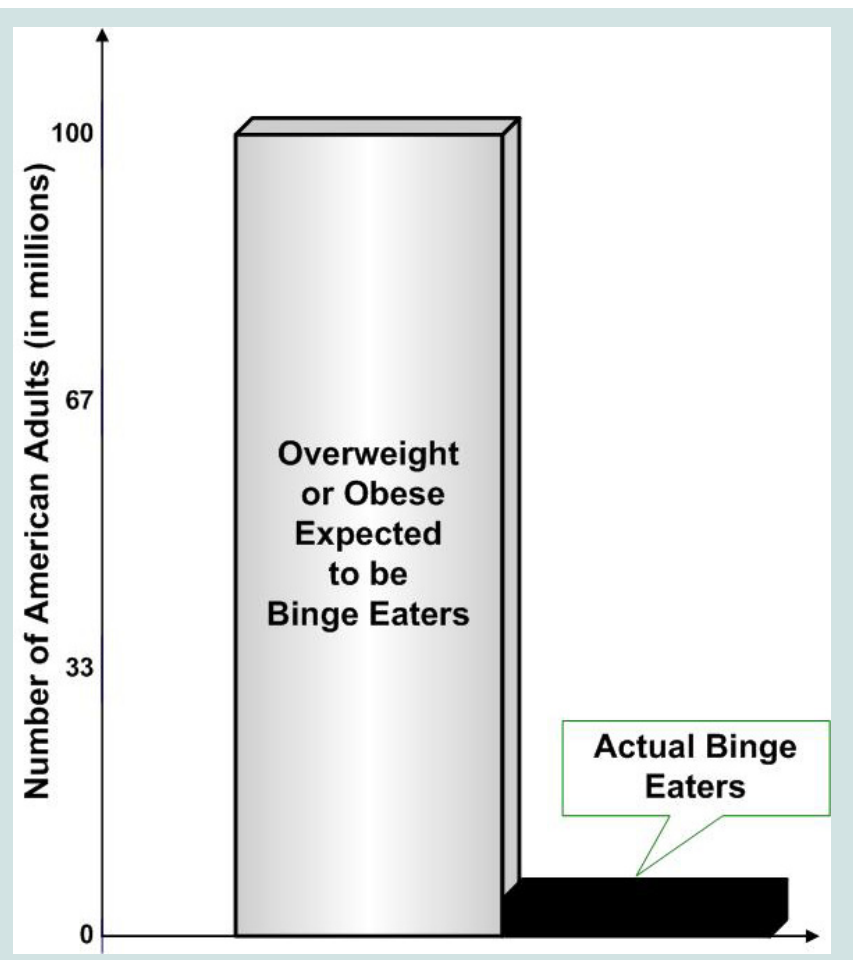

Figure 2: Estimated number of American adults who would be expected to be diagnosed with Binge eating disorder based on the food addict model versus those who were actually diagnosed as such in the survey by Hudson et al. (2007)

than that. Binge eating alone is far less of an intractable problem than an addiction.

Lent, Eichen, Goldbacher, Wadden, and Foster studied a much larger sample of overweight and obese adults $(\mathrm{N}=178)$ over a much longer period of time ( 6 months) [17]. They determined that $15 \%$ of those adults met the YFAS definition of food addict. Based on their support for the food addiction concept, they expected their food addicts to struggle significantly more than the non-addicts to stay involved in the program and lose weight. That did not happen. The food addicts attended just as many sessions and lost just as much weight as the non-addicts.

Pepino, Stein, Eagon, and Klein examined the effects of bariatric surgery on those classified by the YFAS as food addicts versus nonfood addicts [25]. They found that symptoms of food addiction decreased dramatically by nine months post-surgery for $93 \%$ of their participants. But, most relevant to the current paper, they also found that their food addicts lost just as much weight as their to non-addicts.

The findings from these three studies suggest that self-reported food addiction may not disrupt weight management. Three studies with null findings, two of which were statistically under-powered, do not make a definitive case one way or the other. However, perhaps the Yale Food Addiction Scale just identifies people who strongly believe they eat for emotional reasons. After all, many overweight people and others believe that emotional distress causes weight problems more than anything else [26]. They may not understand the powerful influence of other factors that cause excess weight gain, like genetics, excess fat cells and related enzymes and hormones, sedentary living, and eating too much fat. If subsequent research continues to demonstrate minimal measurable effects of food addiction on weight management, that raises a key question: If food addiction does not affect weight loss, then why continue to use this seemingly invalid concept?

\section{Expert Opinions}

Potson and Haddock summarized a great deal of research devoted to understanding the degree to which addictive notions apply to obesity [27]. Neither the editors, nor any of their many contributors came to the conclusion that obese people are best characterized as food addicts. For example, Haddock and Poston summarized the research in their book, concluding that foods that we eat generally do not have mood altering effects that resemble drugs at all: "The whole foods typically consumed in the American diet generally have not been found to have significant psychopharmacological [drug-like] or addictive properties (p.143).” [28].

Brownell and Gold recently published an even larger and more ambitious edited book, Food and Addictions [2]. They asserted in their book that consumption of high sugar foods may essentially "hijack the brain and override will." However, even these experts concluded, "Relatively small numbers of people might merit the label 'food addict;"' and, that interventions for these relatively small numbers of 'food addicts' "can be seen as helping those in need but not having a public health impact on large populations (p.439)."

\section{Research Suggests the Harmful Effects of the Food Addict Conceptualization}

The population of the USA harbors a great deal of stigma for those with mental disorders [29,30]. Those suffering substance abuse disorders, or "addicts", are no exception. Labeling obese people as food addicts applies this stigma to this group, which already suffers weight bias? The food addiction notion creates far more problems for weight controllers than it is worth. Several lines of research support this conclusion.

\section{Medical model vs. social learning model}

In a study contrasting the medical and social learning models, Fisher and Farina taught undergraduates from one of the two perspectives [31]. The first was the classic medical model which views problems as symptoms of underlying disorders. Diagnosing these disorders is supposed to enable therapists to match treatments to the various types of disorders effectively. The food addict notion fits well with the medical model, viewing food addicts as diagnosed patients with additional underlying and abnormal mental problems. An alternative view, the social learning model, asserts that problems in living often occur because people learn maladaptive ways of handling challenges. As such, they can unlearn those patterns and change by setting new goals, problem solving, and taking action. Participants who received the social learning messages actually viewed change more optimistically and worked on their own issues more consistently during the course. The medical model that oriented people to medical-disease concepts, like the food addict perspective, can decrease active and effective efforts to change.

Optimism and perceived control 
Viewing weight problems as caused by an addiction can lead to substantial pessimism about the prospect of changing. Scheier and Carver defined dispositional optimism as the global expectation that good things will be plentiful in the future and bad things, scarce [32] Peterson summarized the research on dispositional optimism noting that optimism affects self-regulation when people face impediments to achieving their goals [33]. Optimism leads to continued efforts to attain the goal, whereas pessimism leads to giving up. Studies on optimism [32,33] viewed in this way showed that relatively optimistic people tend to feel happier and to engage challenges in more active and effective ways. If the food addict idea breeds pessimism, then it also leads to sadder moods and more difficulties with the process of changing lifestyles. Having control, or perceiving control, increases motivation, coping, and problem solving [34]. The food addiction notion suggests that eating is beyond the control of those who are obese. This view fosters pessimism and may impede healthy behavior change.

\section{The Weight Controller Athlete}

People often view obese individuals, in very sharp contrast to athletes, as weak, neurotic, stupid, and slovenly $[7,35]$. This weight stigmatization adds difficulty to the already great challenge of weight control. We offer a more useful, empowering view of people who are overweight and obese: they face the challenges of weight loss as athletes, not food addicts.

Becoming a long-term weight controller is much like becoming a good athlete [13]. People trying to lose or control weight experience tremendous resistance from their bodies from biological factors (e.g., excess fat cell; differential hormones and enzymes [insulin, Lipoprotein Lipase, Leptin, Grehlin, Adiponectin]; adaptive thermogenesis; setpoints [13]). Weight controllers also face biological resistance in the forms of fatigue, muscle soreness, and other physical sensations. Similarly, athletes must push their bodies beyond what is comfortable in order to achieve their goals. Athlete's bodies would certainly rather rest and do other things than practice very deliberately and intensely for the 4-hours+ per day required for maximum success, often pushing their bodies to the point of developing over-use injuries and then having to rehabilitate and move on [36].

Learning to become a long-term weight controller also requires the learning and mastery of new skills (nutrition, exercise, selfmonitoring). Performance in sport requires similar mastery of new skills to maximize strength, speed, and perform best under pressure. Finally, success in both weight control and athletics require a specific mental approach, a consistent and unrelenting focus to achieve a goal, a healthy obsession $[12,13,37]$.

A healthy obsession is defined as "a sustained preoccupation with the planning and execution of target behaviors to reach a healthy goal" [13]. For example, a healthy obsession for a successful weight controller is the focus and determination necessary to achieve consistency in self-monitoring food intake, choosing healthy low fat foods, and exercising frequently. A healthy obsession for an athlete is similar, but instead of controlling weight, its goal is to sustain that daily preoccupation and execution to train the body and mind for maximum performance. The benefits of this mindset to athletes are obvious, but empirical evidence indicates the utility of it to weight controllers as well. For example, Gierut, Pecora, and Kirschenbaum found that weight controllers who adhered to the Healthy Obsession Model $[12,37]$ had much greater success than those who did not. They also found that successful weight controllers exhibited attitudes and sources of motivation that were remarkably similar to those of elite athletes.

\section{Conclusions}

Undoubtedly, weight loss and control are difficult tasks. There are two ways to conceptualize obese people who want to lose weight. The first is that these people are addicts, addicted to food like someone would be addicted to heroin or alcohol. This view fosters helplessness, pessimism, and inaction, ultimately increasing the probability of negative health outcomes. We offer a competing view of obese people who want to lose weight: They are weight controller-athletes. The community of medical and psychological providers has a choice. We can accept the view that the vast majority of obese people are food addicts. With this, we must also accept the consequences. However, we can reject the notion of food addiction as a primary cause of obesity and promote and test a more empowering view. It is time to accept the weight controller-athlete.

\section{References}

1. Ludwig DS, Majzoub, JA, Al-Zahrani A, Dallal GE, Blanco I, et al. (1999) High glycemic index foods, overeating, and obesity. Pediatrics 103: E26.

2. Brownell KD, Gold MS (2012) Food and addiction: Scientific, social, legal, and legislative implications. In Brownell KD, Gold MS, Food and addiction: A comprehensive handbook, Oxford, New York, p: 439-446.

3. Gearhardt AN, Corbin WR (2012) Food addiction and diagnostic criteria for dependence. In Brownell KD, Gold MS, Food and addiction: A comprehensive handbook, Oxford, New York, p: 281-284.

4. American Psychiatric Association (2000) Diagnostic and statistical manual of mental disorders (4th ed, Text Revision). Washington, DC.

5. Massara EB (1980) Obesity and cultural weight valuations: A puerto rican case. Appetite 1: 291-298.

6. Rand CSW, Kuldau JM (1990) The epidemiology of obesity and self-defined weight problem in the general population: Gender, race, age, and social class. Int J Eat Disord 9: 329-343.

7. Wadden TA, Womble LG, Stunkard AJ, Anderson DA (2002) Psychosocial consequences of obesity and weight loss. In T Wadden, AJ Stunkard, Handbook of obesity treatment, Guilford, New York, p: 144-169.

8. Fitzgibbon ML, Stolley MR, Kirschenbaum DS (1993) Obese people who seek treatment have different characteristics than those who do not seek treatment. Health Psychol 12: 342-345.

9. Greenfield SF, Crisafulli MA (2012) Co-occuring addiction and psychiatric disorders. In Brownell KD, Gold MS, Food and addiction: A comprehensive handbook, Oxford, New York, p: 47-52.

10. Krawczyk R, Kirschenbaum DS, Gierut KJ (2014) Over-medication of Obese adolescents in the USA: Preliminary findings [Not Published].

11. Brownell KD, Gold MS (2012) Food and addiction: A comprehensive handbook, Oxford, New York.

12. Kirschenbaum DS (2010) Weight loss camps in the US and the Immersion-toLifestyle Change model. Child Obes 6: 318-323.

13. Kirschenbaum DS (2011) The Wellspring weight loss plan. BenBella Books, Dallas, Texas.

14. Kirschenbaum DS, Craig RD, Kelly KP, Germann JN (2007) Immersion programs for treating pediatric obesity: Follow-up evaluations of Wellspring 
Citation: Kirschenbaum DS, Krawczyk R. The Exaggeration of Food Addiction: Most Weight-Controllers are Athletes, not Addicts. J Obes Bariatrics. 2015;2(2): 6.

ISSN: $2377-9284$

Camps and Academy of the Sierras, a boarding school for overweight teenagers. Obes Manag 3: 261-266

15. Hudson JI, Hiripi E, Pope HG, Kessler RC (2007) The prevalence and correlates of eating disorders in the National Comorbidity Survey replication. Biol Psychiatry 61: 348-358.

16. Burmeister JM, Hinman N, Koball A, Hoffmann DA, Carels RA (2013) Food addiction in adults seeking weight loss treatment: Implications for psychosocial health and weight loss. Appetite 60: 103-110.

17. Lent MR, Eichen DM, Goldbacher E, Wadden TA, Foster GD (2014) Relationship of food addiction to weight loss and attrition during obesity treatment. Obesity (Silver Spring) 22: 52-55

18. Thaxton L (1982) Physiological and psychological effects of short-term exercise addiction on habitual runners. Int J Sport Psychol 4: 73-80.

19. McGuire MT, Wing RR, Klem ML, Hill JO (1999) Behavior strategies of individuals who have maintained long-term weight losses. Obes Res 7: 334341.

20. Wing RR, Hill JO (2001) Successful weight loss maintenance. Annu Rev Nutr 21: 323-341.

21. AbuSabha R, Achterberg C (1997) Review of self-efficacy and locus of contro for nutrition- and health-related behavior. J Am Diet Assoc 97: 1122-1132.

22. Foreyt JP, Goodrick GK (1994) Impact of behavior therapy on weight loss. Am J Health Promot 8: 466-468.

23. Ogden CL, Carroll MD, Kit BK, Flegal KM (2014) Prevalence of childhood and adult obesity in the United States, 2011-2012. JAMA 311: 806-814.

24. Gearhardt AN, Corbin WR, Brownell KD (2009) Preliminary validation of the Yale Food Addiction Scale. Appetite 52: 430-436.

25. Pepino MY, Stein RI, Eagon, JC, Klein S (2014) Bariatric surgery-induced weight loss causes remission of food addiction in extreme obesity. Obesity (Silver Spring) 22: 1792-1798.

26. Bray GA (2012) Overview of therapy for obesity in adults. In Basow D UpToDate, Waltham, UpToDate 2011.

27. Poston WSC, Haddock CK (2000) Food as a drug, Binghamton, Haworth, New York.

28. Haddock CK, Poston WSC (2000) Food as a drug: Conclusions. In Poston WSC, Haddock CK, Food as a drug, Binghamton, Haworth, New York.

29. Corrigan $P$ (2004) How stigma interferes with mental health care. Am Psychol 59: 614-625.

30. Sartorius N (2007) Stigma and mental health. Lancet 370: 810-811.

31. Fisher JD, Farina A (1979) Consequences of beliefs about the nature of mental disorders. J Abnorm Psychol 88: 320-327.

32. Scheier MF, Carver CS (1992) Effects of optimism on psychological and physical well-being: Theoretical overview and empirical update. Cognit Ther Res 16: 201-228.

33. Peterson C (2000) The future of optimism. Am Psychol 55: 44-55.

34. Kobasa SC (1979) Stressful life events, personality, and health: An inquiry into hardiness. J Pers Soc Psychol 37: 1-11

35. Herbozo S, Tantleff-Dunn S, Gokee-Larose J, Thompson JK (2004) Beauty and thinness messages in children's media: a content analysis. Eat Disord 12: $21-34$.

36. Ericsson KA, Charness N (1994) Expert performance: Its structure and acquisition. Am Psychol 49: 725-747.

37. Gierut KJ, Pecora KM, Kirschenbaum DS (2012) Highly successful weight control by formerly obese adolescents: A qualitative test of the healthy obsession model. Child Obes 8: 455-465. 